\title{
POLÍCIA MILITAR COMO SOLUÇÃO PARA VIOLÊNCIA ESCOLAR: UMA ANÁLISE DA REAÇÃO DOCENTE
}

\author{
POLICÍA MILITAR COMO SOLUCIÓN PARA violencia en la escuela: un \\ ANÁLISIS DE LA REACCIÓN DE LA ENSEÑANZA
}

\section{MILITARY POLICE AS SOLUTION FOR SCHOOL VIOLENCE: an analysis of TEACHER REACTION}

RESUMO: Diante do aumento do fenômeno da violência escolar foi iniciado, em 2011, na Rede estadual de ensino do Rio de Janeiro, o Programa Estadual de Integração na Segurança. O objetivo da pesquisa foi analisar a reação dos docentes frente ao programa. A pesquisa resultou numa investigação qualitativa de base explicativa, tendo como instrumento de coleta de dados entrevistas semi-estruturadas. Identificamos que a maioria dos docentes conhece pouco o programa e a forma como a escola se integrou. A pesquisa concluiu que os docentes vêm reagindo a inserção da polícia militar de forma difusa, sendo possível dividi-los em três categorias: os professores resistentes, os professores que consentem e os professores resilientes.

PALAVRAS-CHAVE: Reforma gerencial. Polícia militar. Reação docente.

RESUMEN: El aumento en el fenómeno de la violencia escolar se inició en 2011, las escuelas públicas de Río de Janeiro, el Programa Estatal de Integración de Seguridad. El objetivo de la investigación fue analizar la reacción de los profesores fuera del programa. La investigación dio lugar a una investigación de base explicativa cualitativa, como herramienta de recolección de datos de entrevistas semiestructuradas. Se encontró que la mayoría de los profesores sólo saben del programa y cómo se integró la escuela. La encuesta encontró que los maestros han respondido a insertar la policía militar de forma difusa, y se puede dividir en tres categorías: los maestros resistentes, maestros que den su consentimiento y profesores resilientes.

PALABRAS CLAVE: Gestión de la reforma. Policía militar. Profesor de reacción.

\footnotetext{
${ }^{1}$ Doutor em Educação pelo Programa de Pós-graduação em Educação (PPGE) da Universidade Federal do Rio de Janeiro (UFRJ) com apoio da Coordenação de Aperfeiçoamento de Pessoal do Ensino Superior (CAPES) e Professor Adjunto do Departamento Educação e Sociedade (DES) e do Programa de PósGraduação em Educação, Contextos Contemporâneos e Demandas Populares (PPGEduc) na Universidade Federal Rural do Rio de Janeiro (UFRRJ). Email:rodrigo1281@yahoo.com.br

${ }^{2}$ Graduada em Pedagogia pela Universidade Federal Rural do Rio de Janeiro (2016) e Discente do Programa de Pós-Graduação em Educação, Contextos Contemporâneos e Demandas Populares (PPGEduc) na Universidade Federal Rural do Rio de Janeiro (UFRRJ). Email: rural.paula@gmail.com
} 
ABSTRACT: Faced with the increase in the phenomenon of school violence, the State Program for Integration in Security was initiated in 2011 in the State Education Network of Rio de Janeiro. The objective of the research was to analyze the teachers' reaction to the program. The research resulted in a qualitative investigation with explanatory basis, having as an instrument of data collection semi-structured interviews. We identified that most teachers know little about the program and how the school integrated itself. The research concluded that teachers have been reacting to the insertion of the military police in a diffuse way, being possible to divide them into three categories: resistant teachers, teachers who consents and resilient teachers.

KEYWORDS: Management reform. Military police. Teacher reaction.

\section{Introdução}

O presente artigo apresenta os resultados da investigação sobre a inserção da polícia militar nas instituições públicas de ensino da Educação Básica, no contexto de emergência de novos modelos de gestão do trabalho escolar e políticas de combate à violência nas escolas. A pesquisa realizou investigação sobre à inserção do Programa Estadual de Integração na Segurança (PROEIS) nas escolas públicas da rede estadual de ensino do Estado do Rio de Janeiro e a reação docente, a partir de uma investigação empírica em uma unidade de ensino. O objetivo da pesquisa foi analisar a inserção da policia militar no contexto da escola pública, através de programas de combate à violência nas escolas, e seus desdobramentos. O objetivo específico foi compreender a reação dos docentes a esta inserção policial nas escolas públicas.

A investigação sobre a reação dos docentes ao PROEIS foi realizada através de uma pesquisa qualitativa de base explicativa, tendo como instrumento de coleta de dados entrevistas semi-estruturadas com os docentes do Colégio Estadual Antônio Houass, localizado na Metropolitana II, no bairro do Méier, na cidade do Rio de Janeiro. A escolha da escola se deu pelo quantitativo de alunos que fica em torno de 1.351 (mil trezentos e cinqüenta e um) alunos distribuídos nos $1^{\circ}, 2^{\circ}$ e $3^{\circ}$ ano do Ensino Médio, caracterizando o universo dos discentes em um público jovem em situação de vulnerabilidade social e também por possuir em seu quadro de funcionários mais 100 (cem) professores, lembrando que o PROEIS está implementado na escola.

\section{A recomposição burguesa e a reforma gerencial da administração pública}


Diante da crise instaurada que impôs o fim do "ciclo de ouro" do capitalismo, o Estado de Bem Estar Social passou a ser apontado como a causa da crise nos países capitalistas e o principal empecilho para sua superação. Nesse sentido, o movimento de recomposição burguesa, baseado num conjunto de teses formuladas por intelectuais liberais que, desde a década de 1940, formularam contra a ampliação da atuação estatal, se unem num movimento que ficou conhecido como a Contra-Reforma do Estado. Nessa conjuntura um dos principais intelectuais está Friederich August Von Hayek, principal representante da Escola Austríaca de Economia e que desenvolve crítica ao intervencionismo estatal através do livro "Caminhos para Servidão" no ano de 1944 no qual aponta para os riscos do projeto de "Estado de bem estar social" da socialdemocracia.

O objetivo primordial deste movimento era desfazer o "Estado de bem estar social", erguido durante o "período de ouro" do capitalismo, no contexto da guerra fria e da luta ideológica contra o socialismo. A crítica central produzida por Hayek (1994) foi dirigida às experiências de intervenção estatal com desdobramento no aumento dos direitos dos trabalhadores, à constituição de uma rede de seguridade social, enfim, a qualquer ação que viesse macular a relação de exploração do trabalho nas sociedades capitalistas. Todos os intelectuais que eram favoráveis às ideias de Friedrich Hayek se uniram em uma espécie de sociedade para combater o Keynesianismo, eles eram de acordo com Perry Anderson altamente dedicados e organizados para o objetivo ao qual se propunham. Nesse sentido Anderson (1995) analisou que:

Hayek e seus companheiros argumentavam que o novo igualitarismo (muito relativo, bem sucedido) deste período, promovido pelo Estado de bem-estar, destruía a liberdade dos cidadãos e a vitalidade da concorrência, da qual dependia a prosperidade de todos. (ANDERSON, 1995, p.10)

De acordo com Anderson (1995), o discurso defendido por esses intelectuais era de que a desigualdade social era algo positivo para o capitalismo, pois impulsionava a competição entre os indivíduos. Um capitalismo sem qualquer intervenção estatal que prejudicasse as relações produtivas do capital era o modelo perseguido por esse ideário neoliberal. Friedrich Hayek (1995) criticava o poder atuação dos sindicatos, principalmente do movimento operário, pois reivindicavam mais direitos sociais que implicava em mais gastos sociais por parte do Estado e isso diminuía as bases de acumulação de capital. 
No Brasil, no decorrer da década de 1990, através da Reforma Gerencial, o Estado brasileiro passou por diversas mudanças na gestão pública tendo como referência o modelo de empresas privadas, baseado em conceitos e métodos gerenciais para a gestão do trabalho no serviço público. Neste contexto, o sistema público de educação no país também sofreu alterações na gestão do trabalho escolar. A escola pública no Brasil passou por diversas transformações nos últimos trinta anos, segundo diversos autores (LEHER, 2010; NEVES, 2005; SHIROMA, 2002; LAMOSA, 2014). De acordo com (SHIROMA 2002), o panorama das reformas ocorridas no Brasil nos anos de 1990, seguiram o modelo implantado na Inglaterra, sob a tutela de Margareth Thatcher. Denegriu valores relacionados às políticas e que favoreciam a população, acontecendo, então, uma contra reforma, gerando transformações de valores educacionais, culturais, e sociais. uma política pública e completo.

A reforma gerencial do Estado teve início no primeiro mandato de Fernando Henrique Cardoso (1995-2004), tendo sido definida através do Plano Diretor da Reforma do Aparelho do Estado, em 1995, e inspirada nas reformas gerenciais que ocorreram, desde a década 1980 em países membros da OCDE (Organização para a Cooperação e Desenvolvimento Econômico). Naquele momento o Brasil passava por uma reorganização de forças políticas e econômicas (setores do empresariado nacional) que enxergaram no ajuste neoliberal a saída para a crise pela qual o país estava passando, acentuada diante do fracasso do Plano Collor (1990-1992) no combate à inflação e na retomada das taxas de crescimento econômico. Nessa conjuntura destacouse o cenário de crise econômica pela qual o país vinha atravessando, desde a década 80 , e que era marcado por um conjunto de características: desemprego estrutural, aumento da inflação, dívida externa (moratória) e abertura comercial. O discurso neoliberal, impetrado pelo governo e pelo empresariado, era difundido na imprensa: o Estado precisa ser mais eficiente e menos burocrático.

O diagnóstico era de que o Estado havia crescido muito em termo de pessoal e principalmente em termos de custeio e despesas. Esse crescimento ocorreu, segundo Bresser Pereira, de forma distorcida. Nessa conjuntura a reforma do Estado dizia respeito, sobretudo, a redefinição da sua atuação, delegando ao setor privado e ao setor "público não-estatal", categoria nova e apresentada pelos reformadores, aquelas atividades que não são especificamente estatais (BRESSER-PEREIRA,1997) concomitantemente com o processo de globalização. 
Nessa conjuntura o Brasil inicia em 1995 A Reforma Gerencial do Estado brasileiro através do MARE (Ministério de Administração Federal e Reforma do Estado) entre 1995 a 1998, onde papel do Estado foi reformulado a priori na esfera federal. A frente do MARE Luiz Carlos Bresser Pereira então Ministro da Fazenda nos primeiros quatro anos do governo FHC, formulou as propostas da Reforma Gerencial do Estado de 1995. As propostas apresentadas por Bresser Pereira foi pautada na administração por resultados, ou seja, trouxe a metodologia de funcionamento das empresas privadas para a burocracia estatal, com a justificativa de tornar o Estado mais eficiente no que tange à prestação de serviços de monopólio do Estado, como por exemplo, saúde, educação e segurança, com a desculpa de que o Estado não conseguia ofertar serviços de qualidade.

$\mathrm{Na}$ atual conjuntura observa-se que a reforma contribuiu muito pouco efetiva para a diminuição dos indicadores sociais e também no que diz respeito à desburocratização estatal gerando um sentimento de desapontamento. Nota-se a deterioração dos serviços públicos e também de todo o aparato estatal o que gerou uma maior ineficiência do Estado, contrariando as justificativas que deram origem à sua implantação através do Plano Diretor.

\section{A reforma educacional e a agenda Educação para Todos}

Com intuito de explicitar os fundamentos políticos e ideológicos que determinaram o modo como a Reforma Neoliberal foi sendo construída no estado brasileiro, a partir da década de 1990, e que resultou numa série de outras reformas tendo como uma das mais significativas a Reforma da Educação. A Reforma educacional do Estado brasileiro seguiu as recomendações dos diversos organismos internacionais (Banco Mundial) e por países desenvolvidos, e consistia no cumprimento de uma série de exigências em que países em desenvolvimento teriam que executar uma reestruturação política e econômica para se alinharem ao capital globalizado. Nessa conjuntura os países em desenvolvimento como os que fazem parte da América Latina e da Ásia foram inseridos nessa agenda.

A partir da década de 1990 a TCH (Teoria de Capital Humano) passa por uma ressignificação, e retorna ao palco das discussões entre ou seja, para atender a nova demanda da reprodução do capital devido à crise no contexto socioeconômico do anos 
1990, se faz necessária o seu recrudescimento no sentido de centrar nas ações individuais dos trabalhadores a responsabilidade de se manter no emprego através de investimentos particulares na sua formação profissional. Porém esse investimento não garante que o indivíduo se mantenha ou consiga um emprego surge então o conceito de empregabilidade. Isso devido a conjunto de fatores tais como desemprego estrutural e inflação pelos quais os países em desenvolvimento estavam passando.

Com o advento do modelo neoliberal como sistema econômico hegemônico os países em desenvolvimento passaram a se submeter aos desmandos de organizações internacionais como medida de superação da crise. De acordo com o Banco Mundial necessário que o cidadão do século XXI, terá que dominar os códigos da modernidade:

A melhoria das aptidões e da capacidade do trabalhador é essencial para o êxito econômico numa economia global cada vez mais integrada e competitiva. Os investimentos em capital humano podem melhorar o padrão de vida familiar, expandindo as oportunidades, aumentando a produtividade, atraindo investimentos de capital e elevando a capacidade de auferir renda (BANCO MUNDIAL, 1995, p. 42)

A TCH serviu perfeitamente como prerrogativa para a elaboração das políticas educacionais difundias pelos organismos internacionais e implementadas por seus países membros no contexto da crise estrutural do capital a partir da década de1990 nos países em desenvolvimento em particular a América Latina. Inúmeros organismos multilaterais, intelectuais e educadores publicaram artigos e documentos que serviram de base para a implantação das políticas públicas voltadas para educação, a exemplo do Banco Mundial, BIRD, BID, UNESCO, FMI, UNICEF, PNUD, Cepal e etc. Nesse sentido a educação toma lugar de destaque no cenário das reformas sendo o caminho pelo qual as nações irão se desenvolver com equilíbrio e com justiça social.

Propõe-se para o projeto educativo um novo conceito de educação: educação ao longo da vida, que possibilitasse a constituição de uma sociedade educativa e aprendente. A missão da educação do século XXI de acordo com o Relatório Delors é envolver todos os processos que levem as pessoas, desde a infância até ao fim da vida, a um conhecimento dinâmico do mundo, dos outros e de si mesmas, combinando de maneira flexível os quatro pilares de aprendizagem. Esse tipo de educação possibilitaria o desenvolvimento harmonioso, o recuo da pobreza, da exclusão social e a vivência de uma democracia, objetivos que seriam alcançados através de quatro tipos de aprendizagem: aprendera conhecer, aprender a fazer, aprender a ser e aprender a viver 
junto. O Relatório Delors prenuncia algo que hoje ocorre: mecanismos de recompensas aos professores que obtiverem melhores resultados entre seus alunos. Os professores devem possuir características como competência, profissionalismo e devotamento.

Nessa conjuntura do contexto da reforma educacional sugerida pela Unesco, destaca-se o Programa para reforma educacional da América Latina e Caribe (PREAL). O PREAL surge a partir do Projeto Principal de Educação para a América Latina e Caribe (PROMEDLAC) iniciado em 1980, o projeto, encerrado em 1996, ano de início do PREAL, ambos estão articulados com a Conferência Mundial Educação para Todos e estão subordinadas à Organização das Nações Unidas para a Educação, a Ciência e a Cultura (UNESCO).

Para melhor compreensão o PROMEDLAC é a sigla que indica a reunião de ministros de Educação convocados pela Unesco, são realizadas encontros periódicos para traçar diretrizes a avaliar os avanços e os retrocessos das políticas educacionais implementadas na America Latina e Caribe. Dessas discussões podemos identificar alguns objetivos que foram evidenciados, a exemplo da importância num primeiro momento de colocar a educação no centro das estratégias de desenvolvimento tanto na esfera econômica quanto social, e direcionando mais recursos financeiros para o setor educacional mais precisamente em investimentos em infraestrutura, o que levou a esses países o aumento do endividamento. Num segundo momento as discussões estiveram voltadas para o aspecto gestacional das entidades educacionais. Significa dizer na prática que o Estado passa a ter um novo modelo de Gestão centrado na flexibilidade, buscando o apoio da sociedade civil, estabelecendo alianças público-privado priorizando a qualidade e equidade. E num terceiro momento melhorar a qualidade do serviço prestado através de mecanismos de avaliações nacionais e regionais das instituições de ensino, não menos obstantes os professores também passaram a ser o foco das políticas neoliberais para educação, principalmente no aspecto formativo das carreiras de licenciatura da educação básica. Todas essas interfaces identificadas acima e expostas de formas sintetizada, revelam a priori que as orientações do PREAL possuem grande área abrangência e que o mesmo atua através de um conglomerado de redes, ou como o próprio PREAL diz: "alianzas". Este articula com as entidades internacionais e abarca um número expressivo de associações, órgãos dos governos, organizações não governamentais e fornece consultorias para a elaboração de políticas educacionais estaduais e municipais nos países latino-americanos. O programa atua como um importante formador de opinião, pois reúne um grande número dos 
intelectuais especialistas em educação que estão alinhados direta ou indiretamente com suas orientações, ligados entre si para a formação do consenso hegemônico voltado para o capital agora no contexto das políticas neoliberais. Evidencia-se que o PREAL intervém diretamente nas políticas educacionais dos países periféricos, e que pode ser compreendido a partir do conceito de "intelectual orgânico" desenvolvido por Gramsci (1982).

A reforma educacional do estado brasileiro materializada sob a forma de políticas públicas se configurou numa ressignificação do papel do Estado, agora propagador de uma cultura cidadã onde a sociedade civil pode interagir nos assuntos estatais através da democracia participativa. Segundo Lamosa e Macedo (2015).

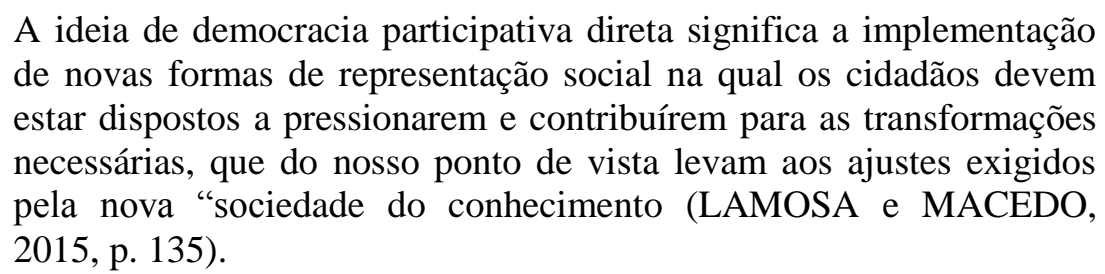

Essa ideia de participação social esta intrinsecamente ligada ao novo modelo gerencialismo estatal. Nesse contexto o Estado amplia sua capacidade de regulação na medida em que transfere para a sociedade civil parte de sua "responsabilidade" oferecendo um papel político maior. Em 1990 o país passa por eleições diretas, e elege para o cargo de presidente Fernando Collor de Mello que assume claramente uma postura em consonância com a agenda neoliberal deliberada anteriormente pelo Consenso de Washington (1989) e tendo como foco central o ajuste da economia brasileira às exigências de reestruturação global da economia, com aberturas prematuras do mercado aos produtos internacionais. Muitos setores da economia nacional não suportaram a concorrência com os produtos importados, a indústria nacional entra em colapso. $\mathrm{Na}$ área da educação e para atender aos empresários do setor Collor retira o controle estatal sobre as instituições privadas que passaram a ser reguladas pelo mercado e reduz o orçamento para as universidades públicas acirrando os conflitos no campo da educação superior deflagrando massivas greves.

Nessa conjuntura em 1993, após o impeachment do presidente Collor, é feita a publicação do Plano Decenal de Educação para Todos no governo tampão de Itamar Franco o qual traçava metas locais de 1993 a 2003, a partir dos acordos firmados em Jomtien, para a melhoria da educação nacional. Contudo a expressão "para todos", tornara-se um problema porque no Brasil a educação básica compreende desde a 
educação infantil até o ensino médio,o que não fazia dos planos da Conferência. Outro problema foi que o NEBAS (Necessidades Básicas de Aprendizagem), indicaria como seria ministrado o ensino. Isto é, ensino diferente para extratos sociais diferentes fortalecendo o dualismo histórico da educação brasileira.

O governo de Fernando Henrique Cardoso (FHC) foi marcado pela concretização das reformas, inclusive as que já estavam em andamento após a aprovação da Constituição de 1988 (CF). Dentre elas a reforma educacional do estado brasileiro. O processo que delineou a Nova LDB de 1996 tal como a conhecemos atualmente, começou a tramitar na Câmara Federal em dezembro 1988 com do projeto Lei $\mathrm{n}^{\circ} 1.258 / 88$, de autoria do Deputado Otávio Elísio, que versa sobre as bases da educação nacional, marco histórico que inicia as discussões sobre o tema. Nesse sentido, inicia-se um amplo processo de discussão, proposição e negociação da LDB a partir de grupos de trabalho, audiências públicas, seminários temáticos, debates e encontros por todo o país, ou seja, a participação da sociedade, do movimento dos trabalhadores da educação, sindicatos, entidades científicas, acadêmicas e estudantis de todo o Brasil; apresentou em sua primeira versão um grande avanço, pois foi formulada coletiva e democraticamente.

A formação para o trabalho impulsiona as políticas do MEC no sentido de uma educação minimalista, o governo através do Decreto $n^{\circ} 2208 / 97$ separa o ensino profissionalizante da formação propedêutica, ou seja, para o governo não era necessário um jovem aprender sociologia na formação para o mercado de trabalho, mas sim aprender o ofício propriamente dito sem contar o tempo para a formação desse jovem seria bem maior e o custo bem mais elevado para o governo. Leher faz uma crítica a esse tipo de ensino quando diz que "A meta era a formação superficial da massa trabalhadora, objetivando a difusão de habilidades instrumentais e a socialização de certo ethos cultural pró-sistêmico, afim ao padrão de acumulação então em curso.” Foi dessa maneira que a educação brasileira foi sendo delineada.

Mecanismos de avaliação por competências foram implementadas pelo MEC, com pressuposto de melhorar os serviços educacionais de todo o país. Neste sentido foi sendo erguido um grande sistema centralizado de avaliação sob a organização do Instituto Nacional de Estudos e Pesquisas Educacionais (Inep), que passou a ser responsável não apenas pelo Censo Escolar, mas também pela sistematização dos indicadores educacionais gerais como: Sistema Nacional de Avaliação da Educação Básica (SAEB), Exame Nacional do Ensino Médio (ENEM), Exame Nacional de 
Cursos (Provão), o Censo Escolar e o índice de Desenvolvimento da Educação Básica (IDEB).

\section{A violência escolar e os novos modelos de gestão do trabalho}

O objetivo desta seção é discutir a relação entre os aspectos do modelo gerencial adotado pelo estado brasileiro, a partir da década de 1990, e a ampliação da oferta de vagas escolares e a violência escolar como um de seus desdobramentos. Em particular para relevância deste artigo o recorte se dá a nível estadual e mais especificamente o Estado do Rio de Janeiro, a partir da implementação da Gestão Integrada da Escola (GIDE), formulada pelo instituto Falconi, a qual foi apresentada pela SEEDUC-RJ como novo modelo gestão da rede estadual de educação, em 2011, após a rede estadual de ensino ter ocupado a vigésima sexta posição no ranking dos estados no IDEB no ano anterior. Com o objetivo declarado de melhorar os índices nas avaliações externas a SEEDUC-RJ implanta a GIDE como novo modelo de gestão do trabalho escolar.

A escola pública no Brasil se expandiu enormemente entre as décadas de 1970 e 2000, destacadamente a partir da década de 1990. Este crescimento não foi acompanhado pelo aumento dos valores do financiamento da educação pública. Em todo este período o financiamento da educação pública brasileira nunca ultrapassou os $3 \%$ do produto Interno Bruto (PIB). Este crescimento das escolas brasileiras, tanto em termos do número de matrículas, quanto em suas responsabilidade, sem um respectivo aumento do financiamento, produziu como efeito uma espécie de "ampliação para menos" da escola brasileira.Segundo (ALGEBAILE, 2009) a função da escola foi ressignificada com o processo de reformas iniciado a partir da década de 1990 e com a nova LDB de 1996. Nessa perspectiva somente através da educação seria possível reduzir as desigualdades sociais e combater a pobreza utilizando como justificativa a Teoria do Capital Humano. A partir dessa conjuntura a ampliação da ofertas de vagas na educação básica, com o objetivo de diminuir os índices de evasão escolar e analfabetismo se caracterizou em políticas educacionais marcadas pelo assistencialismo onde foram incorporados no cotidiano escolar um conjunto de responsabilidades e funcionalidades que não são típicos da escola como o desenvolvimento de hábitos primários de alimentação, higiene pessoal e etc. 
Neste contexto, diversos autores têm identificado a relação entre este processo de "ampliação para menos" das escolas públicas e a intensificação da precariedade do trabalho escolar. Esta precariedade é formada por diversos fatores, incluindo a violência escolar, tema no campo educacional de diversas pesquisas. $\mathrm{O}$ fenômeno da violência no cenário escolar não é algo novo, e muito menos pontual, países como Estados Unidos, Portugal e o Brasil ratificam que esse é um problema mundial, nesse sentido diversos trabalhos, tentam traçar um diagnóstico, expor soluções possíveis através de projetos de cunho sociais desenvolvidos tanto por educadores como pela sociedade civil, porque não se trata somente de um assunto restrito ao ambiente escolar, a violência adentrou aos muros da escola num movimento de fora para dentro e se tornou um desafio de todas esferas sejam elas políticas,sociais e econômicas e por causa da sua complexidade não deve ser analisado isoladamente.

Segundo (SPOSITO, 2001) a violência escolar se manifestava nos anos de 1980, em depredações do patrimônio escolar; já no período compreendido entre o final da década de 1990 a 2000 constatou-se que no foco das pesquisas existe a predominância nas relações interpessoais violentas entre alunos, professores e funcionários, que se apresentam de formas físicas com agressões físicas, brigas e depredações e verbais como ameaças, ofensas, bullyng, segregações, humilhações publicas, palavras agressivas e tendo como vítimas tanto alunos quantos professores e funcionários. $\mathrm{Na}$ busca de desvendar as causas da violência escolar (ARAÚJO, 2001) é categórico em dizer que a democratização do acesso à escola “[...] não representou uma real democratização do acesso ao saber e à cultura letrada.", retomando o conceito desenvolvido por ALGEBAILE (2009) sobre a "ampliação para menos" do ensino básico. A violência escolar nada mais é do que um dos desdobramentos das políticas públicas educacionais gerencialistas elaboradas pelo MEC e que ao longo desse período vem interferindo no fazer pedagógico e na formação dos professores para se ajustar a essa nem tão recente realidade.

Nesse sentido percebe-se que com o agravamento da violência escolar políticas públicas de segurança vêm se adentrando nas políticas educacionais através de programas que vão desde a inserção do policial militar no cotidiano escolar como no caso do estado do Rio de Janeiro e São Paulo com o Programa Segurança na Escola até mesmo a entrega da gestão escolar para batalhões escolares num processo de militarização das escolas que tinham altos índices de violências registrados com o aval do Estado como no caso de algumas escolas no Estado de Goiás. 
No Rio de Janeiro, os desdobramentos da reforma gerencial na educação têm se materializado, segundo Lamosa e Macedo (2015), através da instituição da Gestão Integrada da Escola (GIDE), instituída, desde 2011, a partir da assinatura do convênio entre a Secretaria de Estado de Educação do Rio de Janeiro (SEEDUC-RJ) com a empresa Falconi Consultoria. Através da GIDE foi estabelecido um conjunto de diretrizes para a gestão do trabalho escolar, com a instituição de novos mecanismos de regulação do trabalho das unidades escolares, protocolos de funcionamento, avaliações e metas. Neste sentido, diversos programas foram instituídos na Rede Estadual de ensino com vistas à melhoria da gestão das escolas. Entre estes está o Programa Estadual de Integração na Segurança (PROEIS), instituído em 2011, mesmo ano de implementação da GIDE, no interior das escolas da Rede pública de ensino do estado do Rio de Janeiro.

O PROEIS foi instituído pelo governo do Estado do Rio de Janeiro, através do Decreto n. ${ }^{\circ}$ 42.875, de 15 de março de 2011, através de uma parceria entre a Secretaria Estadual de Segurança (SESEG-RJ) e a Secretaria Estadual de Educação (SEEDUCRJ). O PROEIS possui como uma de suas finalidades definidas: manter, restaurar, e promover medidas de ordem pública nos espaços urbanos, como meio de reduzir índices de criminalidade firma convênio para a inserção e atuação do policial militar no ambiente escolar, a fim de coibir e reprimir algumas situações de violência nas escolas e oferecer maior tranqüilidade e segurança à comunidade escolar garantindo segurança às crianças e jovens da rede estadual. (HTTP://www.rj.gov.br/web/seeduc/exibeconteudo? Article-id=1446345).

Segundo levantamento feito pela SEEDUC-RJ em 2012, as escolas da rede estadual contempladas com o PROEIS, apresentaram melhoria no rendimento e na assiduidade dos alunos, inclusive houve aumento significativo de participação no Saerj das escolas que tem o programa em contraposição com as escolas que não tem. No início do programa cerca de 90 escolas da rede foram selecionadas para implementação do PROEIS, e em maio de 2013 o número de escolas saltou para duzentos e vinte unidades, e o número de policiais também aumentou, passou de dois mil para seis mil. (HTTP://www.rj.gov.br/web/seeduc/exibeconteudo? Article-id=1557698. Esses dados serviram para ratificar o posicionamento da SEEDUC-RJ diante das críticas ao programa.

O PROEIS se tornou alvo de críticas por parte do SEPE (Sindicato dos Profissionais de educação) e um dos pontos criticados é uso de arma de fogo utlilizado 
pelos policiais militares no interior das unidades escolares. Em resposta segundo a SEEDUC-RJ o policial atua de forma preventiva e está preparado para tal serviço. O uso de armas; ele sabe tanto usá-las como não usá-las, deixando-as na cintura. A maioria das escolas que solicitou o PM foi por causa de invasão e depredação do patrimônio público, ou para dar mais segurança na saída e entrada dos estudantes. (http://www.rj.gov.br/web/seeduc/exibeconteudo?article-id=909519). Com intuito de padronizar as ações do policial, em 2013 foram desenvolvidos cursos de capacitação de modalidade de ensino á distância. Assim policial que desejar participar do PROEIS deverá fazer inscrição na EVPMERJ (Escola Virtual da Polícia Militar do Estado do Rio de Janeiro) - criado pela Polícia Militar- e concluir o curso como um dos pré-requisitos, além de possuir requisitos em sua vida funcional que já o habilitam, previamente, para participar do programa.

O PROEIS, é uma medida que permite que os policiais militares possam trabalhar voluntariamente em seu horário de folga mediante gratificação, cumprem turnos de doze horas, trabalham fardados e armados no sentido de inibir possíveis atos de violência que possam ocorrer, principalmente de fora para dentro da escola, a prática de pequenos delitos como, por exemplo, furto de computadores, merenda escolar, depredações da estrutura física da escola, ameaças ao corpo docente e a outros alunos, entre outros. Na prática é a própria escola através do seu corpo diretivo quem solicita a adesão ao PROEIS, por meio de um levantamento explicando a real necessidade de se ter um policial armado dentro na unidade escolar. Essa solicitação é enviada para a SEEDUC que decide se programa irá atender aquela determinada escola.

\section{A reação dos professores a entrada da Polícia Militar na escola pública}

A presença da polícia militar no interior das escolas públicas tem acontecido nos últimos anos em vários estados do país e vem ocorrendo de formas muito distintas, variando em muitos aspectos, desde seu objetivo, até as formas de contratação. No Rio de Janeiro, por exemplo, policiais militares entram nas escolas para oferecer palestras, realizam rondas escolares e, desde 2012, vêm realizando o trabalho através do PROEIS. A inserção do profissional da segurança pública nas escolas vem produzindo uma série de contestações por parte do Sepe (Sindicato Estadual dos Profissionais de Educação do Rio de Janeiro) que no primeiro ano de implantação do programa publicou nota 
denunciando diversos problemas que vinham acontecendo em algumas escolas como, por exemplo, o de um policial que esqueceu a arma dentro do banheiro numa escola da Metropolitana seis; o que levou o Sepe a entrar com uma representação contra Governo do Estado no Ministério Público Estadual em oito de maio do mesmo ano cobrando maiores esclarecimentos e também alertando sobre os possíveis malefícios que a presença do policial militar, que cansado por estender sua carga horária, poderia causar colocando risco toda a comunidade escolar. A partir daí o sindicato passou a receber diversas denúncias envolvendo policiais militares. O Sepe ressalta que o policiamento deve ser realizado nas imediações das escolas não em seu interior, pois tanto alunos, professores e funcionários são vítimas de assaltos. De acordo com denúncia recebida pelo Sepe:

O C. E. Júlia Kubitschek em seu texto de abaixo-assinado aponta que 'Em nossa escola não há supostos bandidos que precisem estar sob vigilância policial, está é bem vinda no patrulhamento na rua Caldwell e imediações, onde há décadas, nossos alunos, seus pais, professores e funcionários são vítimas de constantes assaltos, seja durante o dia ou à noite'.(site do Sepe)

O sindicato alerta que a demanda por policiamento se dá fora da unidade escolar. Ao longo da história do desenvolvimento social no Brasil, educação básica e segurança pública se caracterizaram, enquanto atividades predominantemente estatais, por possuírem papéis muitos distintos na sociedade. Professores e policiais são profissionais preparados para atividades laborais completamente diferentes e, ainda neste sentido, recebem formações que não possuem qualquer similaridade. Nesse sentido a necessidade de se entender como se dá dinâmica da relação entre policiais e educadores no ambiente escolar se manifesta com um misto de obscuridades, tensões e conflitos, no sentido de delimitar os papeis que compete a cada um para a resolução da problemática da violência escolar.

Este trabalho visa contribuir, através da pesquisa qualitativa realizada por meio de entrevistas com os docentes da Escola Estadual Antônio Houass, situada no bairro do Méier cercada pelo complexo de favelas do Lins e do Engenho Novo, para compreensão da reação docente a inserção do PROEIS na respectiva unidade de ensino. Ao todo foram entrevistados dezessete professores, incluindo a professora que se encontra no cargo de direção da escola. Foram entrevistados os docentes apenas do turno da manhã, definidos pela disponibilidade dos mesmos nos dias de imersão da pesquisadora na escola. Foram realizadas duas visitas à escola. Na primeira ida à escola foi realizada 
apresentação da pesquisa à direção da escola que autorizou a entrada da pesquisadora e a realização das entrevistas com os docentes. A segunda ida da pesquisadora na escola ocorreu quarenta e cinco dias após a autorização de pesquisa. Este tempo foi fundamental na definição das questões que nortearam a entrevista semi-estruturada realizada na investigação. As questões elaboradas (ver apêndice) foram divididas em dois eixos. O primeiro eixo, referente a identificação do entrevistado e teve como objetivo conhecer os sujeitos da pesquisa. Não estava nos objetivos, nem aparecia na como hipótese da investigação a confusão quanto a função que o policial deve exercer especificamente. $\mathrm{O}$ segundo eixo teve como norte identificar se os docentes conheciam o PROEIS, se participaram da decisão de realizar o pedido para a escola tornar-se participante do programa, qual sua percepção sobre o papel da entrada do policial em relação aos problemas inerentes à violência escolar.

A pesquisa revelou que a adesão da escola ao programa não aconteceu de forma democrática e coletiva, pois a maior parte dos docentes entrevistados disseram desconhecer como o programa chegou à escola e como se deu todo o processo de adesão junto ao convênio entre a Secretaria de Educação e a Secretaria de Segurança, evidenciando uma relação vertical de poder no que se refere ao corpo diretivo da escola. Entre os docentes entrevistados, somente aqueles que compunham a direção da escola sabiam como havia sido realizado o processo de adesão junto ao PROEIS.

A análise da sistematização das entrevistas permite afirmar que a atuação do Policial Militar no interior da escola é compreendida pelos docentes de forma difusa, onde uma parcela acredita que sua função seja apenas de guarda patrimonial, enquanto outra entende que o policial militar exerce a função que se confunde com a de inspetor escolar. Segundo relato do professor 1: “...Vejo até como se fosse mais um membro do corpo de funcionários do colégio, como um inspetor...”. Já segundo o professor 3: “...Eu sei que é Segurança Patrimonial...”. Na busca pela elucidação da questão, a pesquisadora buscou informações nos sites oficiais dos entes do governo estadual envolvidos (SEEDUC-RJ, SESEG-RJ e Governo do Estado). Foi constatado que existe uma variação no discurso apresentado pela SEEDUC-RJ quanto à atividade que o policial em exercício pelo PROEIS deve exercer no interior da escola. Em nota oficial de esclarecimento da SEEDUC-RJ afirma-se que a atividade do policial é distinta a dos zeladores, inspetores e supervisores pedagógicos:

A Secretaria esclarece, ainda, que os policiais militares são sim treinados e estão preparados para fazer o trabalho de segurança e 
preventivo em qualquer ambiente, inclusive nas escolas. A Seeduc informa que, em momento algum do programa, esses policiais foram chamados para atuar como "zeladores, inspetores e supervisores pedagógicos."

(http://www.rj.gov.br/web/seeduc/exibeconteudo?article-id=909519)

data 04/05/2012 - 11:54h - Atualizado em 04/05/2012 - 18:30h

A interpretação formulada pela SEEDUC-RJ, de acordo com trecho destacado, diferencia o trabalho realizado pelo soldado, através do PROEIS, de outras funções existentes nas escolas públicas da rede estadual de ensino. Entretanto, na mesma nota a SEEDUC-RJ afirma que: “... A maioria das escolas que solicitou o PM foi por causa de invasão e depredação do patrimônio público, ou para dar mais segurança na saída e entrada dos estudantes..." (site seeduc). A interpretação da SEEDUC-RJ sobre o trabalho dos soldados do PROEIS varia, portanto, entre a atividade dirigida à guarda patrimonial e ações que se aproximam de funções pré-existentes nas escolas. Não há uma legislação federal que atribua normas para o cargo de inspetor. Os municípios e estados criam as atribuições através de legislações e atos estaduais e municipais. A Secretaria Estadual de Educação do Rio de Janeiro, em concurso realizado em 2013, definiu as seguintes atribuições do inspetor de escola: "Orientar os alunos para uma atitude de zelo com o patrimônio da escola" e "Acompanhar e monitorar alunos nos intervalos e movimentações dentro da escola, bem como na entrada e saída, zelando por conduta de segurança." (SEEDUC/ Rio de Janeiro - Atribuições do Inspetor de Alunos Fonte: http://concursos.smartwaydev.com.br/Concurso/DadosConcurso?id=5).

Em relação ao treinamento dos policiais e devido às inúmeras denúncias divulgadas pelo Sepe junto ao Ministério público Estadual a SEEDUC-RJ em parceria com a SESEG-RJ elaboraram um curso de capacitação on line para os policias militares se familiarizarem com o cotidiano escolar, e que passou a ser pré-requisito essencial para o policial participar voluntariamente do programa. O curso é todo em ambiente virtual com vídeo aulas produzidas pela Secretaria de Educação e também pela Polícia Militar explicando todas as funções dos atores educacionais desde o diretor da escola até o inspetor e todo o conteúdo do curso está separado em duas apostilas onde o policial pode fazer o download, e ao final do referido curso é realizada uma avaliação se o índice de aproveitamento for acima de 5,0 o policial está pronto para integrar o programa e trabalhar nas suas folgas. A plataforma on line se chama Escola Virtual da PMERJ os policiais podem acessar através do endereço eletrônico 
(http://ev.pmerj.rj.gov.br) a capacitação tem a finalidade de habilitar os policiais militares que prestarão serviço do Proeis, no convênio com a Secretaria de Educação.

Observou-se que a maioria dos entrevistados (ver gráfico 3), busca o auxílio do policial militar como o ultimo recurso quando ocorre algum tipo de conflito, de acordo como professor 1: "Quando acontece algum problema em sala, em aula, os professores mesmos resolvem.”. A intervenção policial, segundo os docentes entrevistados, ocorre na maior parte dos casos nas áreas externas às salas de aula. Estes mesmos docentes externaram que identificam o despreparo dos policiais em lidar com os conflitos que permeiam o ambiente escolar. Neste mesmo sentido, o professor 7 argumentou que: "Presenciei uma vez. A abordagem foi muito ruim. A interferência não mediu nenhum conflito, apenas piorou a situação.”. O policial militar, segundo ambos os professores, realiza o papel para o qual foi treinado, ou seja, "reprimir" atos de violência e manter a ordem. Isso ficou explícito quando o professor 7 afirmou: "O policial agiu da forma que um policial age.”. É possível identificar, através da entrevista com os docentes, que a atuação policial no interior das escolas sofre críticas dos docentes e que esta atuação não se restringe à guarda patrimonial.

A interferência na resolução dos conflitos entre os alunos demonstra uma ampliação das funções do policial no interior da escola, para além da guarda patrimonial. Ao realizar tarefas vinculadas à atuação de professores e inspetores escolares, fica evidenciado uma superposição de papeis que corrobora como mais um fator para a expropriação do trabalho docente, produzindo tensões no interior do espaço escolar, como denunciado pelo SEPE-RJ, desde a implantação do PROEIS. Por outro lado, este processo, contraditoriamente, se desdobra, explícita ou implicitamente, numa reação de conformidade docente, mesmo minoritária (ver gráfico 3), através da qual, os professores, mesmo sem ser favoráveis à inserção policial na escola, naturalizam a existência do PROEIS na rede estadual de ensino no Rio de Janeiro.

Dentre os professores que dizem que vêem contribuição na resolução de conflito há os que enfatizam a "sensação de segurança" como relevante que a presença do policial traz para escola e a comunidade escolar, o policial, fardado e armado, pode exercer uma função dissuasiva, no sentido de desestimular ou intimidar o aluno cometer atos infracionais. O aumento dessa sensação é enfatizada no discurso do Governo Estadual e dizem que o PROEIS melhora a qualidade da educação e a participação dos alunos do SAERJ.Em nota publicada no site da SEEDUC-RJ, em 2013, a secretaria diz que as escolas contempladas pelo PROEIS obtiveram maior rendimento e na 
assiduidade, de acordo com levantamento realizado pela própria secretaria cerca de “...57\% das unidades escolares...", pois num ambiente mais seguro tanto alunos como professores podem dedicar-se o processo de ensino-aprendizagem. (http://www.rj.gov.br/web/seeduc/exibeconteudo?article-id=1557698) Acesso 24de Maio 2016.

\section{Considerações finais}

A pesquisa que resultou neste artigo investigou a reação dos docentes à inserção do PROEIS no Colégio Estadual Antônio Houass, localizado no bairro do Méier, na cidade do Rio de Janeiro. No decorrer da pesquisa, foram realizadas entrevistas semiestruturadas com dezenove docentes, incluindo a própria diretora da escola que faz parte do quadro de funcionários concursados lotados na unidade de ensino. As entrevistas foram realizadas no interior da própria escola. Foi possível identificar a partir das entrevistas que a maioria dos docentes não conhece sobre o programa, muito menos a função proposta pelo PROEIS aos policiais no ambiente escolar. Durante as entrevistas foi possível perceber que os professores não participam do processo de adesão da escola ao programa, e que isso fica restrito à esfera da direção da escola.

Contudo, também foi possível identificar que parte dos docentes acreditam que a presença do policial é algo que corrobora com a paz escolar, no que tange a problemática da violência. Porém se mostravam desconfortáveis com o policial dentro da escola mas que isso era importante pois trazia uma sensação de segurança e impedia até certo ponto atos de vandalismo e até mesmo agressões. Todos os entrevistados não souberam dizer quais eram as funções do policial militar, oscilando entre a função de “inspetor escolar" e a função de "guarda patrimonial” contradizendo a SEEDUC quando diz que o policial não exerce função de inspetor ou guarda patrimonial.

A pesquisa concluiu que os docentes entrevistados vêm reagindo de forma difusa, sendo possível dividi-los em três categorias: os professores resistentes, os professores que consentem ativamente e os professores resilientes. No caso destes últimos, foi possível identificar que esta categoria de docentes,caracterizada, por um lado, por uma postura crítica ao PROEIS e à entrada da polícia nas escolas públicas, e, por outro lado, por uma resignação diante das propostas impostas pela secretaria de educação, representou parte importante da reação à inserção da PMERJ na escola em 
que a pesquisa foi realizada, pois demonstravam que a sensação de segurança era fator relevante do programa. Por fim, foi possível identificar a categoria dos professores que representam um consentimento ativo ao PROEIS, tendo cumprido o papel de propor a adesão da escola ao programa. Estes últimos docentes ocupam cargos de direção na escola, sendo sujeitos fundamentais para implementação das políticas oficiais.

\section{Referências}

ANDERSON, Perry. Balanço do neoliberalismo. In: SADER, Emir \& GENTILI, Pablo (orgs.). Pós-neoliberalismo: as políticas sociais e o Estado democrático. Rio de Janeiro: Paz e Terra, 1995, pp. 09-23.

BANCO MUNDIAL. Aptidões para o desenvolvimento. In: Relatório sobre o desenvolvimento Mundial. Washington: Oxford University Press, 1995. p. 42-46.

BRASIL. PLANO DECENAL EDUCAÇÃO PARA TODOS. Ministério da Educação e do Desporto.Ano1993.Disponível em: HTTP://dominiopublico.gov.br. Acessado em 20de abril de 2016.

BRESSER-PEREIRA, Luis Carlos. Os primeiros passos da reforma gerencial do Estado de 1995. Revista Brasileira do Direito Público - RDB, Belo Horizonte, ano 6, n.23,p.145-186.

DELORS, J. et al. Educação: um tesouro a descobrir. São Paulo: Cortez, UNESCO,MEC, 2012.

EVANGELISTA, O. SHIROMA, E. O MORAES, M. C. M.. Os arautos da reforma e a consolidação do consenso: anos de 1990. In: Política Educacional. 4. Ed. Rio de Janeiro: Lamparina, 2007.

FALCONI CONSULTORES DE RESULTADO. Área pública. 2015. <http://www.flaconi.com/segmentos/area-publica. Disponível em: Acesso em: 08 maio 2016.

FDD. Fundação de Desenvolvimento e Gestão-Gestão para resultados sociais. <http://www.fdg.org.br/trajetoria/>. Acessado em 08/05/2016.

FRIGOTTO, G. A produtividade da escola improdutiva: um (re)exame das relações entre a educação e a estrutura econômico-social capitalista. 9. Ed. São Paulo: Cortez, 2010.

GRAMSCI, Antônio. Os intelectuais e a Organização da cultura. Coleção PERSPECTIVAS DO HOMEM. Rio de Janeiro, RJ: Ed. Civilização Brasileira, 1982. 
GURGEL, Cláudio R. M. A gerência do pensamento: gestão contemporânea e consciência neoliberal. São Paulo: Cortez, 2003.

HOBSBAWN, Eric. Era dos Extremos: o Breve século XX(1914-1991). São Paulo, Companhia das Letras, 2003.

LAMOSA, Rodrigo de Azevedo Cruz. Estado, classe social e educação no Brasil: Uma análise crítica da hegemonia da associação brasileira do agronegócio. Rio de Janeiro. Tese de doutorado. Programa de Pós-Graduação em Educação da Universidade Federal do Rio de Janeiro. 2014.

LAMOSA, Rodrigo de A. Cruz; MACEDO, Jussara Marques de. A Regulação do Trabalho Docente no Contexto da Reforma Gerencial da Educação. Revista Contemporânea de Educação, V.10, №20 - Trabalho e Educação - Rio de Janeiro, ano 2015. Disponível em: <https://revistas.ufrj.br/index.php/rce/article/view/2288/2291 Acesso em 28de abril de2016>.

LEHER, Roberto. 25 Anos de Educação Pública: notas para um balanço do período. In. Trabalho, Educação e Saúde: 25 anos de Formação Politécnica no SUS, 2010. Rio de Janeiro; p.127-172.

MESZÁros, Istévan. A Crise estrutural do Capital. 1. Ed..São Paulo:Boitempo,2009.

MARX, Karl. O Capital: Crítica da Economia Política. Livro I.Vol. I. Rio de Janeiro: Civilização Brasileira, 2003, $19^{a}$ edição.

NEVES, L.M.W. (Org.). Direita para o social e esquerda para o capital: intelectuais da nova pedagogia da hegemonia no Brasil. Cap. 3- São Paulo: Xamã, 2005.

SHIROMA Eneida Oto, Maria Célia M. de MORAES, Olinda EVANGELISTA. Política educacional: Os arautos da Reforma e a Consolidação do Consenso: Anos 90. - Cap. II, Rio de Janeiro: DP\&A, 2002.

TIRADENTES, Aparecida de Fátima dos Santos. Pedagogia do Mercado: Neoliberalismo, Trabalho e Educação no Século XXI. 1 ed. Rio de Janeiro: IbisLibris, 2012.

SCHULTZ, Theodore W. O Capital Humano: Investimentos em Educação e Pesquisa. Zahar Editores, Rio de Janeiro, 1971.

\section{Como referenciar este artigo}

LAMOSA; Rodrigo de Azevedo Cruz; GUIMARÃES; Paula Cristina Pereira. Polícia militar como solução para violência escolar: uma análise da reação docente. Revista on line de Política e Gestão Educacional, Araraquara, v.20, n.03, p. 623-643, 2016. Disponível em: <http://dx.doi.org/10.22633/rpge.v20.n3.9683>. ISSN: 1519-9029. 
Submetido em: julho/2016

Aprovado em: setembro/2016 